\title{
Rejuvenated Red Blood Cells
}

National Cancer Institute

\section{Source}

National Cancer Institute. Rejuvenated Red Blood Cells. NCI Thesaurus. Code C133356.

Red blood cells treated to restore cell integ rity with a rejuvenating solution, such as pyruvate inosine. 